\title{
Simple scanometric assay based on DPPH immobilized on pharmaceutical blister for determination of antioxidant capacity in the herbal extracts
}

\author{
Mochammad Amrun HIDAYAT, Prawita SARI, Bambang KUSWANDI * \\ Chemo and Biosensor Group, Faculty of Pharmacy, University of Jember, Tegal Boto Campus-Jember 68121, \\ Indonesia \\ * Corresponding Author. E-mail: b_kuswandi.farmasi@unej.ac.id (B.K.); Tel. +62-331-324 73 6; ORCID No: 0000-0002- \\ 1983-6110.
}

Received: 01 February 2018 / Revised: 01 March 2018/ Accepted: 11 March 2018

\begin{abstract}
A simple scanometric assay for antioxidant capacity of the herbal extracts has been developed based on dry reagent of 2,2-diphenyl-1-picrylhydrazyl (DPPH) immobilized on the pharmaceutical blister. The deep violet color of DPPH solution was regenerated by introducing methanol to each well as sensing zones. The antioxidant capacity of plant extract will proportionally reduce the violet color to form the corresponding yellow color adduct, where the color change was captured by a flatbed scanner. Then, the optical responses toward antioxidant are presented as an averaged value of the red green blue (RGB) color using image color analysis (ImageJ). By using this color value, analytical performance of the antioxidant sensor could be characterized, where it has a linear range between 1-28 mg/L as gallic acid equivalent (GAE), with response time at $10 \mathrm{~min}$. The reproducibility of the antioxidant sensor was good (RSD < 1\%) with the recovery value of $102-105 \%$. The scanometric assay was applied to several herbal extracts, such as sappan wood, guava leaf, and turmeric rhizome. The results obtained are in good agreement with the spectrophotometric method, suggesting that the proposed assay can be used as an alternative method for antioxidant capacity determination.
\end{abstract}

KEYWORDS: scanometry; DPPH; pharmaceutical blister; antioxidant; herbal extract.

\section{INTRODUCTION}

There are a great interest among general public, medical and nutritional experts, and health and food science researchers to know the antioxidant capacity and constituents in the foods that we are consumed [1]. Antioxidant capacity is a widely used term as a parameter to characterize different substances and food samples with the ability to scavenge or neutralizing free radicals. This capacity is associated with the existence of compounds that capable to protect the biological system from dangerous oxidation [2]. There are synthetic radicals which broadly used for determining antioxidant capacity in a spectrophotometry method, such as 2,2'-azinobis-3-ethylbenzothiazoline-6-sulfonic acid (ABTS) [3], 1,1'-diphenyl-2-picrylhydrazyl (DPPH) [4], and N,N-dimethyl-p-phenylendiamine (DMPD) [5]. Among these radicals, DPPH is one of the most widely used due to its relative stability, sensitivity and the technically simple when conducting the assay [6]. It has a deep purple color with showed maximum absorbance around $517 \mathrm{~nm}$. The DPPH method was firstly used by Blois [7] for measuring antioxidant activity of various substances. Then, some authors [4, 8 , 9] developed the method for evaluating antioxidant activity of other substances, and antioxidant capacity of plant extracts as well. Briefly, the method is based on the reduction of the DPPH radical (DPPH•) by an antioxidant (or antioxidants in a plant extract), which causes the radical to change color (mostly pale yellow which indicates its reduced form, the diphenyl picryl hydrazine). The color change can be monitored by using spectrophotometer at 515-520 $\mathrm{nm}$ [10] or by electron spin resonance (ESR) spectrometer [11, 12]. However, most DPPH studies employed spectrophotometer rather than ESR spectrometer.

The classic DPPH spectrophotometric method used a large volume of DPPH solution (1.0-5.0 mL) to conduct the assay [13-18]. Later, the method was successfully done on the microplate reader by using microwell plate as a sample probe [19]. By using this setting, the amount of DPPH and sample solution as extremely reduced, while no significant different parameters (e.g. reproducibility, percentage recovery) were

How to cite this article: Hidayat MA, Sari P, Kuswandi B. Simple scanometric assay based on DPPH immobilized on pharmaceutical blister for determination of antioxidant capacity in the herbal extracts. Marmara Pharm J. 2018; 22 (3): 450-459. 
observed between microplate-based and cuvette-based method within intra-laboratory validation [20]. The microplate-based is continuously used then by some authors as a high throughput screening for antioxidant capacity [21-24].

Recently, optical sensors based on immobilized chemical reagents have gained more attention since they were suited for rapid and low-cost screening applications. This technology was then adopted by some authors to the DPPH-spectrophotometry, in which DPPH was immobilized on solid support matrices such as polymer film [25-27] or glass microfiber [28] as a sensing probe. Briefly, the antioxidant assay was conducted by dipping the DPPH-probe into a cuvette or a microwell containing buffer solution or methanol, followed by sample (antioxidant or antioxidants) addition and incubation for a few minutes, and absorbance read at 450-520 nm. Although the DPPH-probe-based methods showed a good response to numerous antioxidants and were applicable to various beverages and plant extracts, however, they suffered from high cost, laborious, and time-consuming synthetic-immobilization process. Moreover, since expensive analytical instrument such as a spectrophotometer or microplate reader was used to conduct the assay, the sum of operational cost is higher than the classical DPPH-spectrophotometric method. Therefore, the simpler and cost efficient method has to be developed to overcome this problem.

In our previous work, the DPPH solution was immobilized as a dry reagent on a microplate well as a sensing probe [29]. The antioxidant assay was simply performed by addition of ethanolic or methanolic plant extracts to the DPPH-probe. Instead of spectrophotometer or microplate reader, the color change of DPPH-probe as sensing area was captured by using a flatbed scanner. As antioxidant (s) reduced the violet color of $\mathrm{DPPH}^{\bullet}$ to form the corresponding yellow color adduct, the color intensity change was quantitatively measured by color image analysis using image processing programs like Photoshop or ImageJ. In comparison, this probe-based, color image analysis technique known as scanometry has been used for detection of various analytes such as dopamine [30], magnesium ions [31], lead ions [32, 33], thrombin, and mercury ions [34].

On the other hand, the pharmaceutical packaging contributed the highest proportion $(20-30 \%)$ of plastic wastes in city hospitals in the USA [35], therefore, it is possible to use this material (e.g. the wasted pharmaceutical blister pack) as a sensing probe for antioxidant assay. By reusing the blister pack as the antioxidant sensor, it could reduce the plastic waste, which in turn, posing less negative impact on the environment as depicted in the first principle of the green chemistry, where it is better to prevent waste than to treat or clean up waste after it has been produced [36]. The pharmaceutical blister commonly consisted of thermoformed plastic material with ten or twelve cavities as a drug container, and aluminum lid as a covering film to protect the solid pharmaceutical dosage form, e.g. tablet, capsule, from oxygen or humidity contact [36]. The plastic sheet was made from PVC by using high-temperature molding. It showed a transparent property and its "well-like" cavities are suitable for colorimetric assay. The aluminum lid has to be detached from the plastic sheet just before excluded the drugs from all cavities. In this regard, the current work aimed to develop simple antioxidant sensors based on DPPH with a scanometry assay for antioxidant determination in plant extracts. Here, the DPPH solution was immobilized as dry reagents [29] by a surface coating on the blister sheet as the sensing probes. Then, the sensor was set up as scanometric assay to determine the antioxidant capacity of several herbal extracts as in our previous work [29]. This is due to the fact that a pharmaceutical blister has thinner dimension than a microwell plate. Thus, it is more suitable to the scanometry assay since the scattering effect of ambient light is reduced. In addition, since scanometry used an ordinary flatbed scanner to obtain analytical data, the power consumption was extremely low. Hence, the operational cost of the proposed method was cheaper than spectrophotometer or microplate reader-based method.

\section{RESULTS AND DISCUSSION}

\subsection{Antioxidant sensor set-up}

The dry reagent of DPPH as the main component of the antioxidant sensor in this work was fabricated by a surface coating on the bottom of the blister well using DPPH solution. The immobilization of DPPH on the bottom of each well was performed by solvent evaporation as described in our previous work [29]. Here, the construction of the current DPPH-probe was simpler than our previous DPPH-probe, as the pharmaceutical blister was used to substitute a micro-well plate as a solid support (Fig. 1). While other DPPH-probes [25-28] employed many chemicals (e.g. plasticizer, surfactant, buffer) along with various solid support matrices (e.g. polymer film, glass microfiber) and were constructed by high cost, laborious, and time-consuming synthetic-immobilization process. However, in our approach, the developed DPPH-probe 
in this work was simple, low-cost, and eco-friendly. Moreover, since an ordinary document scanner (flatbed scanner) was used in the developed method to obtain an analytical signal (i.e. scanometry), the sum of operational cost is extremely lower than other DPPH-probe methods which employed UV-Vis spectrophotometer or micro-plate reader to conduct the assay.

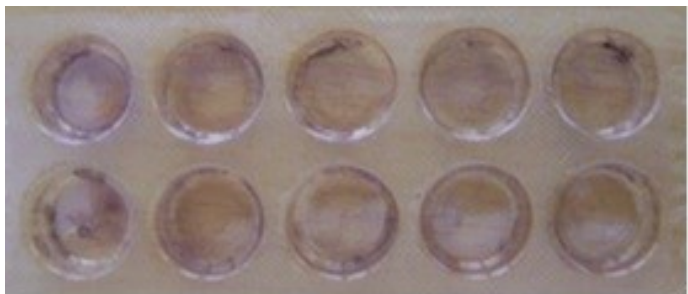

(a)

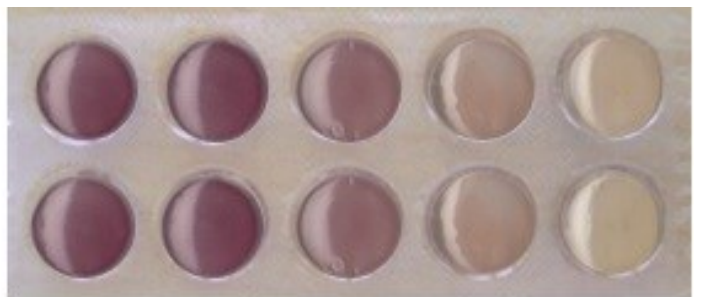

(b)

Figure 1. The immobilized DPPH as dry reagent (a); and the scanned immobilized DPPH after addition of sample solution tested (b).

\subsection{Sensing scheme}

The sensing scheme of the developed optical sensor is laid on the basic mechanism of DPPH method previously described by some authors [7-9]. The purple color of $\mathrm{DPPH} \bullet$ at the sensing probe is reduced by an antioxidant $(\mathrm{AH})$ to the corresponding pale yellow hydrazine $(\mathrm{DPPH} \cdot-\mathrm{H})$ as depicted in Fig. 2. In this regard, $\mathrm{DPPH}^{\bullet}$ accepts an electron or hydrogen radical to become a stable diamagnetic molecule [39]. In conjunction, it was known that phenolic acids (e.g. GA) can work as antioxidant either by donating a hydrogen atom (often called as hydrogen atom transfer) [40] or performing as electron donors (often called as single electron transfer) [41].

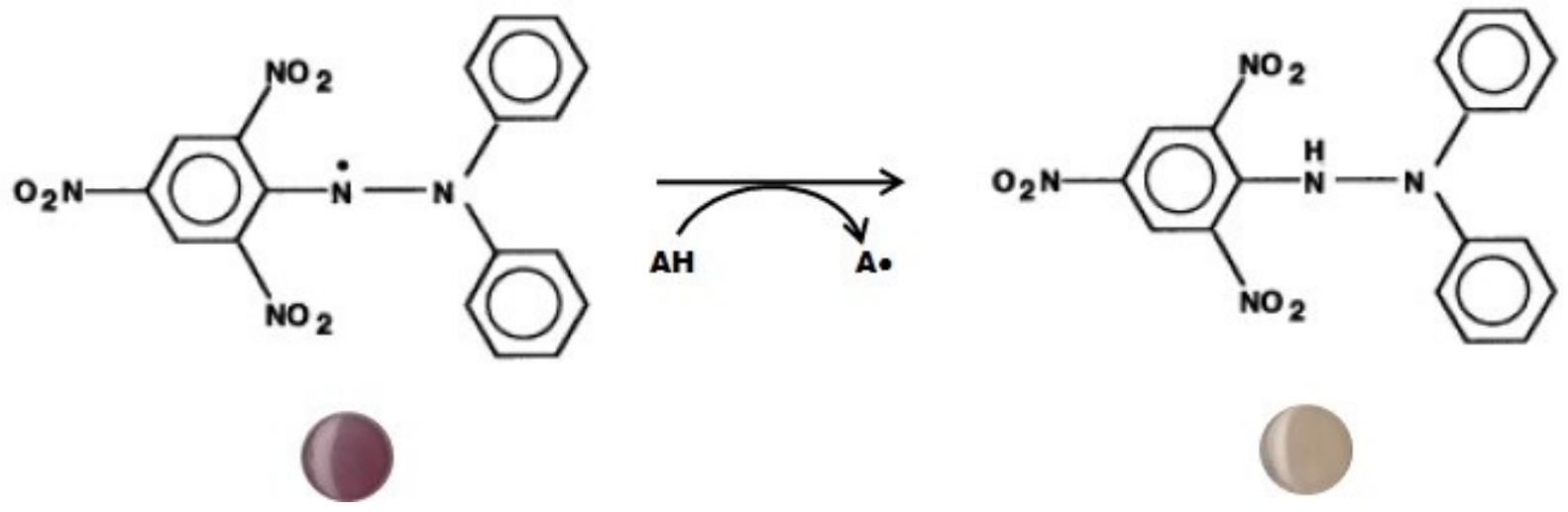

Figure 2. The reaction of DPPH radical with antioxidant (AH).

\subsection{DPPH concentration}

As the DPPH method was already known as one of many colorimetric assays, the proposed antioxidant sensor also worked on the colorimetric-based principle. The color change of the sensor probe by antioxidant addition, in this context, was depended on the concentration of DPPH and GA. Various concentration of DPPH (100, 125 and $150 \mathrm{mg} / \mathrm{L})$ were tested toward a serial concentration of GA (1-23 $\mathrm{mg} / \mathrm{L})$ to construct the calibration curve of GA vs. color intensity $(\triangle \mathrm{RGB})$ of each DPPH concentration as depicted in Fig. 3. Based on its linear correlation and slope, the concentration of DPPH at $125 \mathrm{mg} / \mathrm{L}$ was selected as optimum DPPH concentration. At this DPPH concentration, the slope and coefficient correlations (r) were found to be 1.865 and 0.998 respectively, which showed the highest values among other DPPH concentrations (100 and $150 \mathrm{mg} / \mathrm{L}$ ), as seen in Fig. 3. Thus, the DPPH concentration of $125 \mathrm{mg} / \mathrm{L}$ was applied for further measurements. 


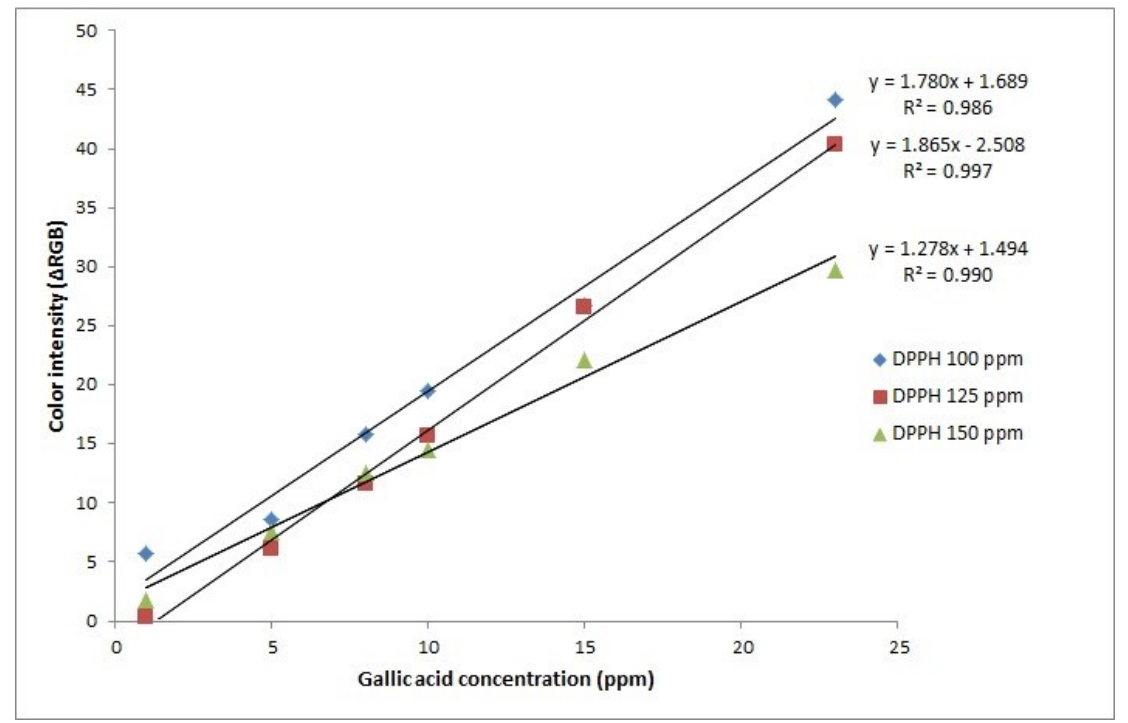

Figure 3. The calibration curve of GA towards color intensity using various DPPH concentrations (100, 125 and $150 \mathrm{mg} / \mathrm{L})$.

\subsection{Response time}

By using GA at $15 \mathrm{mg} / \mathrm{L}$ concentration, the response time of antioxidant sensor was examined and recorded every 2 minutes until the stable color intensity value was obtained. As shown in Fig. 4, after 10 minutes the color intensity was stabilized. Hence, the response time of sensor was 10 minutes and used in all further measurements. In term of operating time, this result was comparable with that obtained by another DPPH-probe method, where caffeic acid (CA), ferulic acid (FA), and GA at a similar concentration (1 mM) gave visible color change within 10 minutes of exposure in the well plate set-up. However, longer operating time ( $\geq 15$ minutes) was observed by using a lower concentration of GA $(0.1 \mathrm{mM})$, which is equal to the concentration of GA in recent work. In comparison, the developed sensor showed faster operating time compared to the conventional microplate-based [22, 23] and DPPH-probe methods [28], since in both methods the absorbance reading was done after 30 minutes. While another conventional microplate-based method [24] took similar operating time as in our developed method, however, it was suffered from cosolvent and buffer addition.

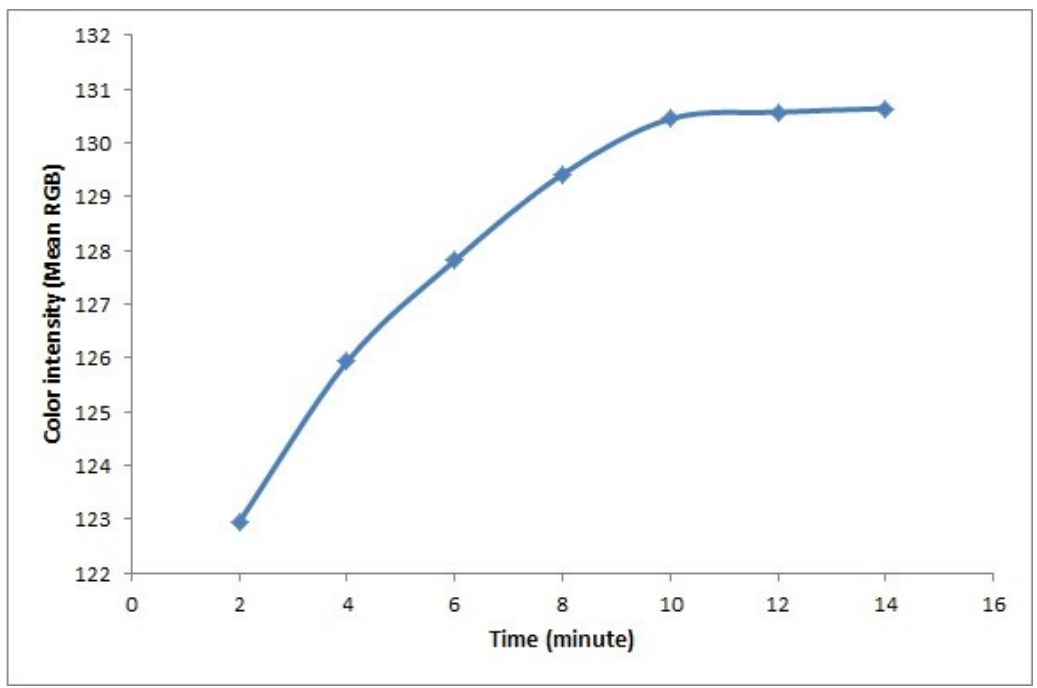

Figure 4. Response time of the antioxidant sensor towards GA (15 mg/L).

\subsection{Antioxidant determination}

In the current work, the calibration curve of GA was constructed by plotting concentration of GA vs. color intensity $(\triangle \mathrm{RGB})$ as sensor response, as it can be seen in Fig. 5 . The linear range of GA was observed in 
the range of $1-28 \mathrm{mg} / \mathrm{L}$ with the coefficient correlation $(\mathrm{r})$ of 0.997 . The detection limit (LOD) of the antioxidant sensor, which is defined as the concentration of GA producing a signal equal to the blank signal plus three times its standard deviation which was 1.208 , was calculated to be $1.725 \mathrm{mg} / \mathrm{L}$. The reproducibility of the sensor response was tested toward $16 \mathrm{mg} / \mathrm{L}$ of GA solution, as depicted in Table 1. Here, the RSD value of sixth replication was lower than $1 \%$, which indicates the developed method has good reproducibility [42].

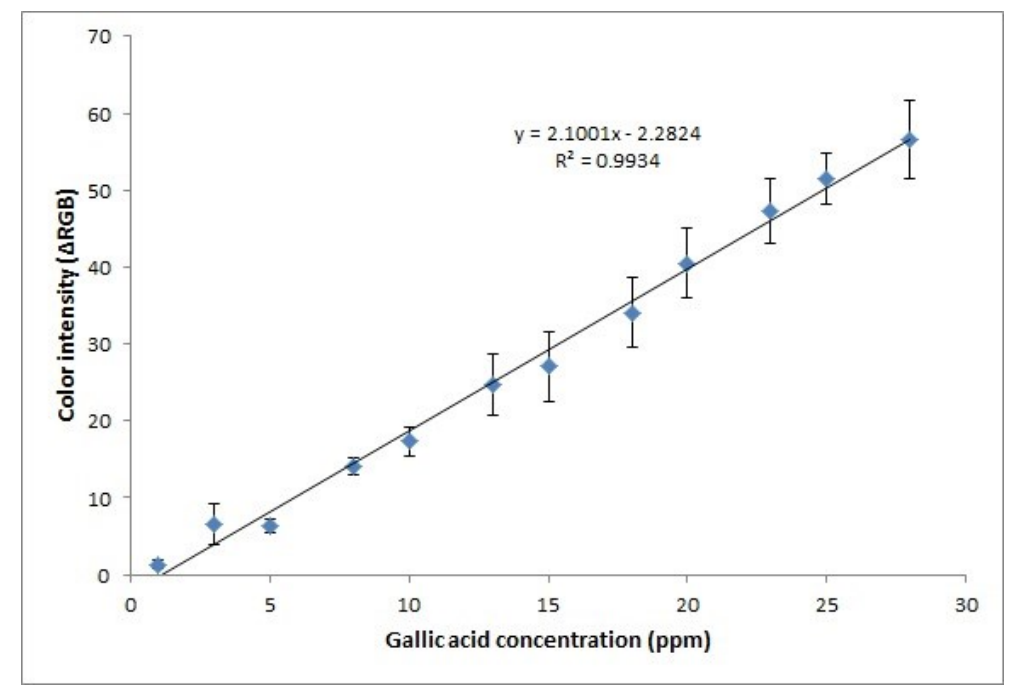

Figure 5. Sensor response towards GA (1-28 mg/L) $(\mathrm{n}=3)$.

Table 1. The antioxidant sensor response towards $16 \mathrm{mg} / \mathrm{L}$ of GA in simulated samples $(\mathrm{n}=6)$.

\begin{tabular}{ccc}
\hline Sample & RGB & $\Delta$ RGB \\
\hline Blank & 79.45 & - \\
1 & 116.83 & 37.380 \\
2 & 116.276 & 36.826 \\
3 & 116.388 & 36.938 \\
4 & 116.551 & 37.101 \\
5 & 115.925 & 36.475 \\
6 & 116.054 & 36.604 \\
\hline & Mean & $\mathbf{3 6 . 8 8 7}$ \\
\hline
\end{tabular}

\subsection{Selectivity}

In order to demonstrate the selectivity of the antioxidant sensor, a study on the effect of potential interference in measuring antioxidant activity was carried out. Oxalic acid, an organic acid naturally found in the plant was chosen as interfering substance since it was recognized as natural antioxidant in thiobarbituric acid reactive substance (TBARS) method [43]. Here, the influence of oxalic acid addition at different ratios (1:1, 1:12, and 1:40) on the antioxidant determination of simulated sample (25 mg/L of GA) was investigated. Results showed that addition of oxalic acid at 1:40 ratio concentration of GA gave 5\% interference to the sensor signal as depicted in Table 2. However, to the best of our knowledge, the high concentration of oxalic acid $(1000 \mathrm{mg} / \mathrm{L})$ never found naturally in a plant sample.

In addition, as inorganic salts can affect the antioxidant activity in DPPH method, their natural existence in certain plant samples can be thought as a potential interference in antioxidant capacity determination. In this regard, ferric chloride was chosen as interfering substance in the similar setting as oxalic acid. The addition of ferric chloride at 1:1 ratio gave $4 \%$ of interference of antioxidant measurement as it can be seen in Table 2. In comparison, the corresponding iron salts, i.e. $\mathrm{FeCl}_{2}$ and $\mathrm{Fe}\left(\mathrm{NO}_{3}\right)_{3}$ at a similar concentration $(25 \mathrm{mg} / \mathrm{L})$ showed DPPH quenching activity at 47 and $14 \%$ respectively in a conventional spectrophotometry method [44]. Thus, it can be deduced that iron salts were potential interferer in antioxidant measurement using the DPPH-based method. 
Table 2. The antioxidant sensor response towards $25 \mathrm{mg} / \mathrm{L}$ of GA and various interfering substances addition at different concentration ratios.

\begin{tabular}{lccc}
\hline Sample & Mean RGB & $\Delta$ RGB & Interference (\%) \\
\hline Blank & 79.365 & - & - \\
GA (25 mg/L) & 127.756 & - & - \\
GA + Oxalic Acid (1:1) & 126.310 & 1.446 & $1.132 \%$ \\
GA + Oxalic Acid (1:12) & 123.332 & 4.424 & $3.463 \%$ \\
GA + Oxalic Acid (1:40) & 121.284 & 6.472 & $5.066 \%$ \\
\hline $\mathrm{GA}+\mathrm{FeCl}_{3}(1: 1)$ & 122.301 & 5.455 & $4.270 \%$ \\
$\mathrm{GA}+\mathrm{FeCl}_{3}(1: 12)$ & 101.963 & 25.793 & $20.189 \%$ \\
$\mathrm{GA}+\mathrm{FeCl}_{3}(1: 40)$ & 81.203 & 46.553 & $36.439 \%$ \\
\hline
\end{tabular}

\subsection{Recovery}

To evaluate the performance of the proposed method in antioxidant determination, a simulated sample containing $12 \mathrm{mg} / \mathrm{L}$ GA was analyzed using antioxidant sensor by standard addition method as recovery test described by Huber [45]. After individual addition of 15, 17, and $20 \mathrm{mg} / \mathrm{L}$ of GA to represent 30,45 , and $60 \%$ of initial GA concentration, the recovery of GA was found to be in the range $100-102 \%$ as depicted in Table 3. This finding suggested that the proposed assay is accurate and has a great potential for determining antioxidant in plant extract samples.

In addition, the stability of the blisters with DPPH was found within 6 months of study, it was still show good response as antioxidant sensor. This is due to the fact that the DPPH was immobilized on the blister in a dry condition (dry reagent), sealed with aluminum foil, and stored in in chiller condition $\left(\sim 4^{\circ} \mathrm{C}\right)$. Thus, it will remain stable as long as the seal was not opened or broken and no contact with the ambient light.

Table 3. The recovery of GA (\%) in simulated samples that obtained by standard addition using the antioxidant sensor.

\begin{tabular}{|c|c|c|c|c|c|c|}
\hline \multirow[b]{2}{*}{$\begin{array}{l}\text { Initial GA } \\
\text { conc.(mg/L) }\end{array}$} & \multicolumn{2}{|c|}{ After $30 \%$ addition } & \multicolumn{2}{|c|}{ After $45 \%$ addition } & \multicolumn{2}{|c|}{ After $60 \%$ addition } \\
\hline & $\begin{array}{c}\text { GA conc. } \\
\text { (mg/L) }\end{array}$ & Recovery (\%) & $\begin{array}{c}\text { GA conc. } \\
\text { (mg/L) }\end{array}$ & Recovery (\%) & $\begin{array}{c}\text { GA conc. } \\
\text { (mg/L) }\end{array}$ & Recovery (\%) \\
\hline 12.125 & 15.650 & 100.714 & 17.709 & 101.527 & 20.075 & 106.000 \\
\hline 13.625 & 17.796 & 104.275 & 20.011 & 106.433 & 21.695 & 103.969 \\
\hline 14.937 & 19.533 & 102.133 & 21.695 & 103.969 & 23.945 & 100.089 \\
\hline & & 102.747 & & 104.286 & & 102.064 \\
\hline
\end{tabular}

\subsection{Application of antioxidant sensor on the plant extracts}

In order to demonstrate the practical use of the antioxidant sensor, various herbal extracts from various parts of the plant were employed, such as sappan wood for bark extract, guava leaf for leaf extract, and turmeric rhizome for roots extract. Here, the herbal extracts were intentionally chosen not only by the apparent color of the tested solutions (i.e. red, green, yellow) but also to represent various parts of the plant used as traditional herbal medicine as exemplified on The Indonesian Herbal Pharmacopoeia [46].

While the developed antioxidant sensor was characterized with GA, the obtained antioxidant capacity of the tested herbal extracts can be validated by comparing with the antioxidant activity of GA since this approach was done in many studies [47-50]. Using the standard calibration curve of GA obtained by scanometry technique, the antioxidant capacity of each extract was calculated and expressed as gallic acid equivalent in $\mathrm{mg} / \mathrm{L}(\mathrm{mg} / \mathrm{L}$ GAE) as described in our previous work [29]. Afterward, the results were compared with that obtained from the DPPH-spectrophotometry method. As seen in Table 4, no significantly different results were observed between two methods on the antioxidant capacity determination. Therefore, the proposed method was in good agreement with the standard spectrophotometric method, and it can be an alternative method for antioxidant capacity determination of the herbal extracts.

In addition, in term of fabrication of the proposed method (DPPH blister-scanometric assay) demanded a lower cost than the DPPH-spectrophotometric method, since it employed the used pharmaceutical blisters and use lower concentration of DPPH $(125 \mathrm{mg} / \mathrm{L})$ with small volume $(300 \mu \mathrm{l})$ compared to the cuvettes or microwell plates $(0.004 \%, 1-3 \mathrm{~mL})$. Hence, each well of the blister will be around 
$37.50 \mu \mathrm{g}$ that is lower compared to $40 \mu \mathrm{g}$ of DPPH in cuvette for $1 \mathrm{ml}$, or even more if it used above $1 \mathrm{~mL}$. Furthermore, in term of the operational cost was also lower as a flatbed scanner used to obtain analytical signals compared to the UV-Vis spectrophotometer or the microplate reader.

Table 4. The result of antioxidant capacity determination ( $\mathrm{mg} / \mathrm{L}$ GAE) of various herbal extracts determined by the antioxidant sensor and the UV/Vis spectrophotometer $(n=3, a=0.05)$.

\begin{tabular}{llll}
\hline Sample extracts & $\begin{array}{l}\text { Antioxidant sensor with } \\
\text { scanometry }\end{array}$ & $\begin{array}{l}\text { UV/Vis } \\
\text { Spectrophotometer }\end{array}$ & Sig. value $(\mathrm{p})$ \\
\hline Sappan wood \#HS01 $(10 \% \mathrm{w} / \mathrm{v})$ & $20.31 \pm 0.09$ & $21.33 \pm 0.70$ & 0.066 \\
Guava leaf\#HS02 $(10 \% \mathrm{w} / \mathrm{v})$ & $23.59 \pm 0.51$ & $23.61 \pm 0.14$ & 0.956 \\
Turmeric rhizome \#HS03 $(0.1 \% \mathrm{w} / \mathrm{v})$ & $22.62 \pm 0.05$ & $22.79 \pm 0.10$ & 0.056 \\
\hline
\end{tabular}

\section{CONCLUSION}

Simple scanometry assay for determination of antioxidant capacity has been developed based on dry reagent of DPPH immobilized onto blister pack. The antioxidant sensor had a linear range of 1-28 $\mathrm{mg} / \mathrm{L}$ with LOD at $1.725 \mathrm{mg} / \mathrm{L}$, and it was found to be reproducible, accurate and selective for antioxidant assay. The proposed assay was comparable with the standard spectrophotometric method and was found to be rapid, easy to operate, low cost and reliable to be used as an alternative method for antioxidant capacity determination in the herbal extracts. Moreover, since the sensor was constructed by using blister of the tablet pack waste, it also helped to reduce pharmaceutical plastic waste, which in turn, posed a low impact on the environment.

\section{MATERIALS AND METHODS}

\subsection{Chemicals}

Gallic acid (GA) and 2,2-diphenyl-1-picrylhydrazyl (DPPH) were obtained from Sigma-Aldrich (USA). Oxalic acid and methanol were purchased from Merck (Germany). All chemicals were of analytical reagent grade and were used without further purification.

\subsection{Herbal sample preparation}

Several herbal samples, such as sappan wood (Caesalpinia sappan L., \#HS01), guava leaf (Psidium guajava L., \#HS02), and turmeric rhizome (Curcuma domestica Val., \#HS03), were obtained from the local market at Jember, Indonesia and were used as the real samples. These herbal samples were authenticated by our herbalist (Ms. Indah Yulia Ningsih) and deposited at Pharmacognosy Laboratory, Faculty of Pharmacy, University of Jember. Herbal samples were air dried, ground, and pulverized until their particle size freely passed through sieve \#100. All herbal powder were extracted using a method described in our previous work [29] with slight modification. Here, the dried herbal powder $(0.5 \mathrm{~g})$ was extracted with methanol (50 $\mathrm{mL}$ ) for an hour at $30^{\circ} \mathrm{C}$ using an ultrasonicator (Elmasonic $\mathrm{S} 180 \mathrm{H}$, Germany). The extracts were then centrifuged at 2,500 rpm for $30 \mathrm{~min}$. Afterward, the supernatants were separated and stored in well-capped tubes prior to antioxidant test at room temperature.

\subsection{Antioxidant determination by spectrophotometry}

The standard spectrophotometry DPPH method, following the previous work [37] with slight modification was used for measuring the antioxidant capacity of plant extracts. In the current work, $200 \mu \mathrm{L}$ of sample solution (diluted extract) was mixed with $800 \mu \mathrm{L}$ of $0.004 \%$ DPPH solution in a cuvette and after $30 \mathrm{~min}$ absorbance of the mixture was read at $515 \mathrm{~nm}$. The antioxidant capacity was expressed as gallic acid equivalent in $\mathrm{mg} / \mathrm{L}$ (mg/L GAE), based on the obtained antioxidant activity of GA from calibration curve with a similar condition.

\subsection{Sensor fabrication}

Single pharmaceutical blister sheet containing ten round-shaped with flat bottom cavities was obtained by collecting from the tablet waste (Tempo Scan Pacific, Indonesia). Before, it used, the well was obtained simply by detaching aluminum lid from the plastic sheet. The plastic sheet was then cleaned and washed with distilled water and methanol consecutively prior to the construction of the sensing probe. Each 
cavity or well which served as a solid support for the immobilized reagent had an internal diameter of 14 $\mathrm{mm}$ and internal volume of about $400 \mu$ l. (Fig. 1).

A solution of DPPH in methanol at various concentrations (100, 125, and $150 \mathrm{mg} / \mathrm{L}$ ) were transferred $(300 \mu \mathrm{l})$ into wells in the blister as the sensing probe. The solvent was then evaporated under a mild condition at room temperature to construct the dry reagent of DPPH as an antioxidant sensor. Afterward, the antioxidant sensor was ready to be used. For long-term use and avoid photodecomposition of DPPH, the antioxidant sensor was sealed with aluminum foil (Fig.1) and stored in chiller condition $\left(\sim 4^{\circ} \mathrm{C}\right)$.

\subsection{Measurement Procedure}

The measurement of the analytical parameter is obtained from the circle area on the bottom of DPPHprobe as the average area of the sensing zone captured as the color change before and after reacting with the extract contained in the sample. For the simple setting and reproducibility reason, the color change of the sensor was captured using a flatbed scanner (CanoScan, LIDE 110, Japan). The scanning resolution of 300 dots per inch (dpi) was applied for image scanning. The color intensity was then analyzed with ImageJ program for Windows.

Since the single color image is constructed from three primary colors: red, green, and blue; thus the digital color images are in the red green blue (RGB) format. If all of the colors are bright at the same intensity, then the color is white. If only red is bright, then the color is red, and so on. In a single RGB image, three layers of different images are overlaid [38]. In this work, the calculated color intensity values ( $\triangle$ RGB) of sensors were obtained by subtracting the color intensity value (mean RGB) of the DPPH solution (control) with the color intensity value (mean RGB) of the tested sample. All of the experiments were carried out in triplicate measurements.

\subsection{Optimization study}

In order to find the optimum DPPH concentration that gives best calibration curve in term of its linear correlation (r), the gallic acid (GA) was used as a standard solution. GA solution was added in different concentration $(1,5,8,10,15$, and $23 \mathrm{mg} / \mathrm{L})$, to each well with $300 \mu \mathrm{l}$ of methanol and $75 \mu \mathrm{l}$ of GA solution were added. After $10 \mathrm{~min}$, the color change of each well was quantified using the measurement procedure, where the calibration curve can be constructed.

Acknowledgements: Thanks to Chemo \& Biosensors Group, Faculty of Pharmacy, University of Jember, for funding this work.

Author contributions: Concept - B.K., M.A.H.; Design - B.K., M.A.H.; Supervision - B.K.; Resource - B.K., M.A.H., P.S.; Materials - P.S., M.A.H.; Data Collection and/or Processing - P.S., M.A.H.; Analysis and/or Interpretation M.A.H.., P.S.; Literature Search - P.S., M.A.H.; Writing - M.A.H., P.S., B.K.; Critical Reviews - M.A.H., P.S., B.K.

Conflict of interest statement: The authors declared no conflict of interest.

\section{REFERENCES}

[1] Huang D, Boxin OU, Prior RL. The chemistry behind antioxidant capacity assays. J Agric Food Chem. 2005; 53: 1841-1856. [CrossRef]

[2] Pyrzynska K, Pękal A. Application of free radical diphenylpicrylhydrazyl (DPPH) to estimate the antioxidant capacity of food samples. Anal Methods. 2013; 5: 4288-4295. [CrossRef]

[3] Miller NJ, Rice-Evans C, Davies MJ, Gopinathan V, Milner A. A novel method for measuring antioxidant capacity and its application to monitoring the antioxidant status in premature neonates. Clin Sci. 1993; 84: 407-412. [CrossRef]

[4] Brand-Williams W, Cuvelier ME, Berset C. Use of a free radical method to evaluate antioxidant activity. LWT Food Sci Technol. 1995; 28: 25-30. [CrossRef]

[5] Fogliano V, Verde V, Randazzo G, Ritieni A. Method for measuring antioxidant activity and its application to monitoring the antioxidant capacity of wines. J Agric Food Chem. 1999; 47: 1035-1040. [CrossRef]

[6] Osman AM. Multiple pathways of the reaction of 2,2-diphenyl-1-picrylhydrazyl radical (DPPH) with (+)-catechin: Evidence for the formation of a covalent adduct between DPPH and the oxidized form of the polyphenol. Biochem Biophys Res Commun. 2011; 412: 473-478. [CrossRef] 
[7] Blois MS. Antioxidant determinations by the use of a stable free radical. Nature. 1958; 181: 1199-1200. [CrossRef]

[8] Bondet V, Brand-Williams W, Berset C. Kinetics and Mechanisms of Antioxidant Activity using the DPPH. Free Radical Method. LWT - Food Sci Technol. 1997; 30: 609-615. [CrossRef]

[9] Sánchez-Moreno C, Larrauri JA, Saura-Calixto F. A procedure to measure the antiradical efficiency of polyphenols. J Sci Food Agric. 1998; 76: 270-276. [CrossRef]

[10] Molyneux P. The Use of the Stable Free Radical Diphenylpicryl-hydrazyl (DPPH) for Estimating Antioxidant Activity. Songklanakarin J Sci Technol. 2004; 26: 211-219. [CrossRef]

[11] Calliste C-A, Trouillas P, Allais D-P, Simon A, Duroux J-L. Free radical scavenging activities measured by electron spin resonance spectroscopy and B16 cell antiproliferative behaviors of seven plants. J Agric Food Chem. 2001; 49: 3321-327. [CrossRef]

[12] Kusšar A, Zupančič A, Šentjurc M, Baričevicč D. Free radical scavenging activities of yellow gentian (Gentiana lutea L.) measured by electron spin resonance. Hum Exp Toxicol. 2006; 25: 599-604. [CrossRef]

[13] Bener M, Özyürek M, Güçlü K, Apak R. Optimization of microwave-assisted extraction of curcumin from Curcuma longa L . ( Turmeric) and evaluation of antioxidant activity in multi-test systems. Records Nat Prod. 2016; 5: 542554 .

[14] Dolinsky M, Agostinho C, Ribeiro D, Rocha GDS, Barroso SG, Ferreira D, Polinati R, Ciarelli G, Fialho E. Effect of different cooking methods on the polyphenol concentration and antioxidant capacity of selected vegetables. J Culin Sci Technol. 2016; 14: 1-12. [CrossRef]

[15] Nisar T, Iqbal M, Raza A, Safdar M, Iftikhar F, Waheed M. Estimation of total phenolics and free radical scavenging of turmeric (Curcuma longa). Am J Agric Environ Sci. 2015; 15: 1272-1277. [CrossRef]

[16] Nirmal NP, Panichayupakaranant P. Antioxidant, antibacterial, and anti-inflammatory activities of standardized brazilin-rich Caesalpinia sappan extract. Pharm Biol. 2015; 53: 1339-1343. [CrossRef]

[17] Pękal A, Pyrzynska K. Effect of pH and metal ions on DPPH radical scavenging activity of tea. Int J Food Sci Nutr. 2015; 66: 58-62. [CrossRef]

[18] Seo J, Lee S, Elam ML, Johnson SA, Kang J, Arjmandi BH. Study to find the best extraction solvent for use with guava leaves (Psidium guajava L.) for high antioxidant efficacy. Food Sci Nutr. 2014; 2: 174-180. doi:. [CrossRef]

[19] Lee SK, Mbwambo ZH, Chung H, Luyengi L, Gamez EJ, Mehta RG, Kinghorn AD, Pezzuto JM. Evaluation of the antioxidant potential of natural products. Comb Chem High Throughput Screen. 1998; 1: 35-46.

[20] Bobo-García G, Davidov-Pardo G, Arroqui C, Vírseda P, Marín-Arroyo MR, Navarro M. Intra-laboratory validation of microplate methods for total phenolic content and antioxidant activity on polyphenolic extracts, and comparison with conventional spectrophotometric methods. J Sci Food Agric. 2015; 95: 204-209. [CrossRef]

[21] Cheng Z, Moore J, Yu L. High-throughput relative DPPH radical scavenging capacity assay. J Agric Food Chem. 2006; 54: 7429-7436. doi:. [CrossRef]

[22] Abderrahim F, Arribas SM, Carmen Gonzalez M, Condezo-Hoyos L. Rapid high-throughput assay to assess scavenging capacity index using DPPH. Food Chem. 2013; 141: 788-794. [CrossRef]

[23] Musa KH, Abdullah A, Kuswandi B, Hidayat MA. A novel high throughput method based on the DPPH dry reagent array for determination of antioxidant activity. Food Chem. 2013; 141: 4102-4106. [CrossRef]

[24] Condezo-Hoyos L, Abderrahim F, Arriba SM, Carmen González M. A novel, micro, rapid and direct assay to assess total antioxidant capacity of solid foods. Talanta. 2015; 138: 108-116. [CrossRef]

[25] Steinberg IM, Milardović S. Chromogenic radical based optical sensor membrane for screening of antioxidant activity. Talanta. 2007; 71: 1782-1787. [CrossRef]

[26] Lee PM, Arsad MSM, Yussoff AC, Lee Kong Hung. Colored thin film for screening and evaluation of antioxidants. In: 2010 International Conference on Science and Social Research (CSSR 2010). IEEE; 2010. p. 717-720. [CrossRef]

[27] Ahn YH, Yoo JS, Kim SH. An antioxidant capacity assay using a polyvinyl alcohol-based DPPH pellet. Bull Korean Chem Soc. 2010; 31: 2557-2560. [CrossRef]

[28] Piletska EV, Piletsky SS, Whitcombe MJ, Chianella I, Piletsky SA. Development of a new microtiter plate format for clinically relevant assays. Anal Chem. 2012; 84: 2038-2043. [CrossRef]

[29] Hidayat MA, Fitri A, Kuswandi B. Scanometry as microplate reader for high throughput method based on DPPH dry reagent for antioxidant assay. Acta Pharm Sin B. 2017; 7(3): 395-400. [CrossRef] 
[30] Abbaspour A, Khajehzadeh A, Ghaffarinejad A. A simple and cost-effective method, as an appropriate alternative for visible spectrophotometry: development of a dopamine biosensor. Analyst. 2009; 134: 1692-1698. [CrossRef]

[31] Shokrollahi A, Hemmatidoust K, Zarghampour F. Determination of magnesium by the solution scanometric method in a coloured titan yellow magnesium hydroxide complex form. J Taibah Univ Sci. 2016; 10: 161-167. [CrossRef]

[32] Chen B, Wang Z, Hu D, Ma Q, Huang L, Xv C, Guo Z, Jiang X. Scanometric nanomolar lead (II) detection using DNA-functionalized gold nanoparticles and silver stain enhancement. Sensors Actuators B Chem. 2014; 200: 310316. [CrossRef]

[33] Vijitvarasan P, Oaew S, Surareungchai W. Paper-based scanometric assay for lead ion detection using DNAzyme. Anal Chim Acta. 2015; 896: 152-159. [CrossRef]

[34] Shi X, Wen J, Li Y, Zheng Y, Zhou J, Li X, Yu H-Z. DNA molecular beacon-based plastic biochip: A versatile and sensitive scanometric detection platform. ACS Appl Mater Interfaces. 2014; 6: 21788-21797. [CrossRef]

[35] Lee B-K, Ellenbecker MJ, Moure-Eraso R. Analyses of the recycling potential of medical plastic wastes. Waste Manag. 2002; 22: 461-470. [CrossRef]

[36] Anastas PT, Warner JC. Green Chemistry: Theory and Practice. Oxford University Press, New York, USA; 1998.

[37] Pilchik R. Blister Packaging. Part I: Rationale and Materials. Pharm Technol. 2000; 68-77.

[38] Ningsih IY, Zulaikhah S, Hidayat MA, Kuswandi B. Antioxidant activity of various Kenitu (Chrysophyllum cainito L.) leaves extracts from Jember, Indonesia. Agric Agric Sci Procedia. 2016; 9: 378-385. [CrossRef]

[39] Kota Miura. Basics of Image Processing and Analysis. 2.1.1. Heidelberg: Centre for Molecular \& Cellular Imaging, EMBL Heidelberg; 2013. http:/ /cmci.embl.de.

[40] Yen GC, Duh P Der, Tsai HL. Antioxidant and pro-oxidant properties of ascorbic acid and gallic acid. Food Chem. 2002; 79: 307-313. [CrossRef]

[41] Dorman HJD, Lantto TA, Raasmaja A, Hiltunen R. Antioxidant, pro-oxidant and cytotoxic properties of parsley. Food Funct. 2011; 2: 328-337. [CrossRef]

[42] Lee SE, Shin H-T, Hwang HJ, Kim JH. Antioxidant activity of extracts from Alpinia katsumadai seed. Phytother Res. 2003; 17: 1041-1047. [CrossRef]

[43] Yuwono M, Indrayanto G. Validation of chromatographic methods of analysis. Profiles Drug Subst Excipients Relat Methodol. 2005; 32: 243-259. [CrossRef]

[44] Kayashima T. Oxalic acid is available as a natural antioxidant in some systems. Biochim Biophys Acta. 2002; 1573: 1-3. [CrossRef]

[45] Al-Dabbas MM, Al-Ismail K, Kitahara K, Chishaki N, Hashinaga F, Suganuma T, Tadera K. The effects of different inorganic salts, buffer systems, and desalting of Varthemia crude water extract on DPPH radical scavenging activity. Food Chem. 2007; 104: 734-739. [CrossRef]

[46] Huber L. Validation and Qualification in Analytical Laboratories, second ed., Informa Healthcare, New York,USA; 2007.

[47] Depkes. Farmakope Herbal Indonesia, first ed., Departemen Kesehatan RI, Jakarta, Republik Indonesia; 2008.

[48] Apetrei CL, Tuchilus C, Aprotosoaie AC, Oprea A, Malterud KE, Miron A. Chemical, antioxidant and antimicrobial investigations of Pinus cembra L. bark and needles. Molecules. 2011; 16: 7773-7788. [CrossRef]

[49] Zhang A, Fang Y, Wang H, Li H, Zhang Z. Free-radical scavenging properties and reducing power of grape cane extracts from 11 selected grape cultivars widely grown in China. Molecules. 2011; 16: 10104-10122. [CrossRef]

[50] Sharma S, Vig AP. Evaluation of in vitro antioxidant properties of methanol and aqueous extracts of Parkinsonia aculeata L. leaves. Sci World J. 2013; 2013: 1-7. [CrossRef]

[51] Lu Y, Shipton FN, Khoo TJ, Wiart C. Antioxidant activity determination of citronellal and crude extracts of Cymbopogon citratus by 3 different methods. Pharmacol Pharm. 2014; 5: 395-400. [CrossRef] 